\title{
T4 stage and preoperative anemia as prognostic factors for the patients with colon cancer treated with adjuvant FOLFOX chemotherapy
}

Min Sung An ${ }^{1}$, Jong Han Yoo ${ }^{1}$, Kwang Hee Kim', Ki Beom Bae ${ }^{1 *}$, Chang Soo Choi ${ }^{1}$, Jin Won Hwang' ${ }^{2}$ Ji Hyun Kim², Bo Mi Kim³ ${ }^{3}$ Mi Seon Kang ${ }^{3}$, Min Kyung $\mathrm{Oh}^{4}$ and Kwan Hee Hong ${ }^{1}$

\begin{abstract}
Background: FOLFOX-based adjuvant chemotherapy is a benefit for high-risk stage II and stage III colon cancer after curative resection. But, the prognostic factor or predictive marker for the efficacy of FOLFOX remains unclear. This study was aimed to identify the prognostic value and cumulative impact of adjuvant FOLFOX on the stage II and III colon cancer patients.

Methods: A total of 196 stage II and III colon cancer patients were retrospectively enrolled in prospectively collected data. They underwent curative resection followed by FOLFOX4 adjuvant chemotherapy. The oncological outcomes included the 5-year disease-free survival (DFS) rate and 5-year overall survival (OS) rate. Cox-regression analysis was performed to identify the prognostic value, and its cumulative impact was analyzed.

Results: The 5-year DFS rate of the patients was $71.94 \%$ and the 5-year OS rate was $81.5 \%$. The prognostic values for the 5-year DFS rate and 5-year OS rate were T4 stage and preoperative anemia in a multivariate analysis. Each patient group who had no prognostic value, single, or both factors revealed $95.35 \%, 69.06 \%$, and $28.57 \%$ in the 5 -year DFS rate, respectively $(p<0.0001)$. The 5 -year OS rate also showed the significant differences in each group who had no prognostic value, single, or both factors revealed $100 \%, 79.3 \%$, and $45.92 \%$, respectively $(p<0.0001)$.

Conclusion: Our results showed similar efficacy to MOSAIC study in stage II and stage III colon cancer patients treated with adjuvant FOLFOX chemotherapy after curative resection. Patients who had T4 stage and/or preoperative anemia showed worse prognosis than patients without any prognostic value. These findings suggest that FOLFOX could not be effective in the patients with T4 stage colon cancer accompanied by preoperative anemia.
\end{abstract}

Keywords: Colon cancer, FOLFOX, T4 stage, Anemia

\section{Background}

Colorectal cancer is the second most common cancer in the USA and the third most common cancer in Korea [1]. The most important treatment for colon cancer is surgical resection. However, $40 \%$ to $50 \%$ of these postsurgical patients eventually experience recurrence or die from metastatic lesions [2,3]. In the 1990s, O'Connell et al. [4] reported low recurrence and mortality rates in patients with stage III colon cancer who had received

\footnotetext{
* Correspondence: bkbsur@yahoo.co.kr

'Department of Surgery, Busan Paik Hospital, Inje University College of Medicine, 75 Bokji-ro, Busanjin-gu, Busan 614-735, Korea

Full list of author information is available at the end of the article
}

5-fluorouracil (5-FU) and low-dose leucovorin (LV) injections as chemotherapy after surgical resection. The Intergroup Trial (INT-0035) reported that administration of 5-FU and levamisole injections as adjuvant chemotherapy after surgery in patients with stage III colon cancer decreases the mortality rate by 33\% [5]. Subsequently, many reports suggested that a 5-FU and LV combination became the standard adjuvant treatment for stage III colon cancer [6,7].

The MOSAIC (Multicenter International Study of Oxaliplatin/5-FU/LV in the Adjuvant Treatment of Colon Cancer) trial reported that the FOLFOX chemotherapeutic regimen, for which oxaliplatin (a third- 
generation platinum derivative alkylating agent) was added to 5-FU and LV, showed a superior disease-free survival (DFS) rate than the 5-FU and LV (LV5FU2) regimen $[8,9]$. Additional follow-up observations of the MOSAIC trial continuously demonstrated that FOLFOX chemotherapy is advantageous in terms of both the DFS and overall survival rates [9]. Thus, the 2013 National Comprehensive Cancer Network (NCCN) guidelines recommend FOLFOX4 or XELOX chemotherapy for patients with high-risk stage II and stage III colon cancer after surgery [10].

However, the 5-year survival rate from each stage, American Joint Committee on Cancer (AJCC) sixth edition staging, showed paradoxically the lower survival rate in stage IIb $(72.2 \%)$ than in stage IIIa (83.4\%) [3]. There should be several poor prognostic factors affecting the survival rate even after the adjuvant chemotherapy. FOLFOX-based adjuvant chemotherapy is a benefit for high-risk stage II and stage III colon cancers after curative resection. But, the prognostic factor or predictive marker for the efficacy of FOLFOX remains unclear. This study was aimed to identify the prognostic value and cumulative impact of adjuvant FOLFOX on the stage II and III colon cancer patients.

\section{Methods}

\section{Subjects}

This retrospective study included 196 patients with colon cancer who were administered FOLFOX4 chemotherapy after radical surgery in the Department of Surgery, Busan Paik Hospital, Inje University College of Medicine between April 2006 and December 2010. The stage of colon cancer were classified in accordance with the sixth edition of the AJCC TNM staging system, and the high-risk stage II and III patients who had been treated with adjuvant FOLFOX chemotherapy were enrolled.

Colon cancer was defined as cancer in which the lower tumor margin was located in the upper part of the peritoneum, and the stage II high-risk group must have at least one of the following factors, including T4a/4b, tumor perforation, bowel obstruction, poorly differentiated tumor, or venous, perineural, or lymphatic invasion. We investigated not only the postsurgical pathological characteristics but also the ASA score and preoperative laboratory findings, which reflected the general state of patients before undergoing treatment, as well as the adverse reactions that developed during chemotherapy. Adverse reactions were examined by dividing them into three categories: 1) neutropenia (cases with grade 3 or 4), 2) gastrointestinal symptoms (diarrhea, patients prescribed loperamide, nausea or anorexia), and 3) peripheral neuropathy (patients prescribed gabapentin). Written informed consent was obtained from the patient for the publication of this report and any accompanying images.

\section{Chemotherapy method and follow-up observations}

LV $200 \mathrm{mg} / \mathrm{m}^{2} /$ day was administered intravenously for $2 \mathrm{~h}$. Then, a bolus IV of 5 -FU $400 \mathrm{mg} / \mathrm{m}^{2}$ was administered, which was followed by intravenous administration of 5 -FU $600 \mathrm{mg} / \mathrm{m}^{2}$ continuously for the remaining $22 \mathrm{~h}$. This regimen was continued for 2 days. Oxaliplatin $85 \mathrm{mg} / \mathrm{m}^{2}$ was infused for $2 \mathrm{~h}$ only on day 1 . A prophylactic antiemetic and sufficient fluid were infused on days 1 and 2 of chemotherapy. This regimen was administered every 2 weeks. The adjuvant chemotherapeutic regimen was carried out for a total of 12 cycles.

Patients were followed up every 3 months for the first 2 years after surgery and every 6 months thereafter for 3 years, for a total of 5 years of follow-up. History, physical examination, and serum carcinoembryonic antigen levels were determined at each follow-up visit. Chest Xray and abdominopelvic computed tomography scans were performed to assess the efficacy of chemotherapy every four cycles and every 6 months after completion of chemotherapy. A colonoscopy was performed annually. Recurrence was identified by imaging studies and colonoscopy and was confirmed by colonoscopic or percutaneous biopsy. Radiologically identified tumor growth within the previous surgical field was considered to indicate recurrence when histological confirmation was not possible.

\section{Statistical analysis}

This study was the observational setting. The oncologic outcome was analyzed with 5-year DFS and 5-year overall survival (OS) rate. Each survival rate was analyzed with the Kaplan-Meier method. Cox proportional hazards model was used for the univariate and multivariate analyses of factors affecting the prognosis. The KaplanMeier method and log-rank test were conducted to compare the DFS and OS rates among risk groups. A $p$ value $<0.05$ was considered to indicate significance. SAS ver. 9.3 (SAS Institute, Cary, NC, USA) was used for the statistical analysis.

\section{Results}

\section{Clinicopathological data}

The mean follow-up period was $61 \pm 31$ months, and among the 219 patients, 23 patients had been lost during their follow-up. A total of 196 patients were included [age range 26 to 76 years, median age 57 years, 112 males $(57.1 \%)$ and 84 females $(42.9 \%)$ ]. In total, 147 patients $(75 \%)$ were $<65$ years, and 49 patients $(25 \%)$ were $\geq 65$ years. A total of 174 patients $(88.8 \%)$ belonged to the category of moderately differentiated tumors and 174 patients $(88.8 \%)$ belonged to the T3 stage, whereas 
Table 1 Clinicopathologic characteristics of the patients

\begin{tabular}{lll}
\hline Characteristic & Number & $\%$ \\
\hline Total patients & 196 & \\
Median age (range) & $57(26$ to 76$)$ & \\
$\quad<65$ & 147 & 75.0 \\
$\quad \geq 65$ & 49 & 25.0 \\
Sex & & 57.1 \\
$\quad$ Male & 112 & 42.9 \\
$\quad$ Female & 84 & \\
Tumor location & &
\end{tabular}

Right

Transverse

Descending

Sigmoid and rectosigmoid

Histologic appearance

Well differentiated

Moderately differentiated

Poorly differentiated

Signet ring cell

Mucinous cell

Lymphovascular invasion (+)

Neural invasion (+)

T stage

$\mathrm{T} 1$

$\mathrm{T} 2$

$\mathrm{T} 3$

T4

$\mathrm{N}$ stage

No

N1

N2

WBC

$<4,000 \times 10^{6} / \mathrm{L}$

$4,000 \sim 10,000 \times 10^{6} / \mathrm{L}$

$>10,000 \times 10^{6} / \mathrm{L}$

Hemoglobin ( $\mathrm{Hgb})$

Female $<12 \mathrm{~g} / \mathrm{dL}$ (anemia) $\quad 50$

Female $\geq 12 \mathrm{~g} / \mathrm{dL}$ (normal)

Male $<14 \mathrm{~g} / \mathrm{dL}$ (anemia) $\quad 66$

Male $\geq 14 \mathrm{~g} / \mathrm{dL}$ (normal) $\quad 46$

Platelet (PLT)

$<140 \times 10^{9} / \mathrm{L}$ (thrombocytopenia)

$140 \sim 440 \times 10^{9} / \mathrm{L}$

$>440 \times 10^{9} / \mathrm{L} \quad 7$

Albumin

$<3.8 \mathrm{~g} / \mathrm{dL}$
Table 1 Clinicopathologic characteristics of the patients (Continued)

\begin{tabular}{lll}
\hline $3.8 \sim 5.3 \mathrm{~g} / \mathrm{dL}$ & 156 & 79.6 \\
Lactate dehydrogenase (LDH) & & \\
$\quad 129 \sim 240 \mathrm{U} / \mathrm{L}$ & 41 & 20.9 \\
$>240 \mathrm{U} / \mathrm{L}$ & 155 & 79.1 \\
Total bilirubin & & 96.4 \\
$0.2 \sim 1.0 \mathrm{mg} / \mathrm{dL}$ & 189 & 3.6 \\
$>1.0 \mathrm{mg} / \mathrm{dL}$ & 7 &
\end{tabular}

Aspartate aminotransferase (AST)

$10 \sim 33 \mathrm{U} / \mathrm{L} \quad 174 \quad 88.8$

$>33 \mathrm{U} / \mathrm{L}$

$22 \quad 11.2$

Alanine aminotransferase (ALT)

$4 \sim 50 \mathrm{U} / \mathrm{L}$

$183 \quad 93.4$

$>50 \mathrm{U} / \mathrm{L}$

$13-6.6$

Protein

$\begin{array}{lll}<6.7 \mathrm{~g} / \mathrm{dL} & 29 & 14.8 \\ 6.7 \sim 8.3 \mathrm{~g} / \mathrm{dL} & 165 & 84.2 \\ >8.3 \mathrm{~g} / \mathrm{dL} & 2 & 1.0\end{array}$

Prognostic model $(\mathrm{T} 4, \mathrm{Hgb})$

$\begin{array}{lll}\text { Low-risk group } & 43 & 21.9\end{array}$

$\begin{array}{lll}\text { Intermediate-risk group } & 139 & 70.9\end{array}$

$\begin{array}{lll}\text { High-risk group } & 14 & 7.2\end{array}$

0.5 Preoperative CEA

$2.5 \leq 5 \mathrm{ng} / \mathrm{mL}$

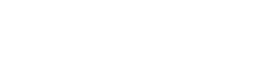

$>5 \mathrm{ng} / \mathrm{mL}$

Postoperative CEA

$$
\leq 5 \mathrm{ng} / \mathrm{mL}
$$

$>5 \mathrm{ng} / \mathrm{mL}$

Side effect

Neutropenia

Gastrointestinal symptoms

CEA, carcinoembryonic antigen; WBC, white blood cell.

86 patients (43.9\%) were in the N1 stage. Of the 196 patients, 158 patients completed a total chemotherapy of
25.5

17.3

33.7

23.5

2.0

94.4

3.6

20.4 12 cycles. Thirty-eight patients did not complete all chemotherapy cycles due to neutropenia, gastrointestinal symptoms (diarrhea, nausea, or anorexia), peripheral neuropathy, or cancer recurrence. Of the 196 patients, 154 (78.6\%) had neutropenia, 36 (18.4\%) had gastrointestinal symptoms, and 40 (20.4\%) had peripheral neuropathy (Table 1).

Analysis of survival rates (DFS, OS) and prognostic factors The 5-year DFS rate of the all patients was $71.94 \%$ and the 5 -year OS rate was $81.5 \%$ (Figure 1). The 5 -year DFS rates of the high-risk stages II and III were $77.78 \%$ and 


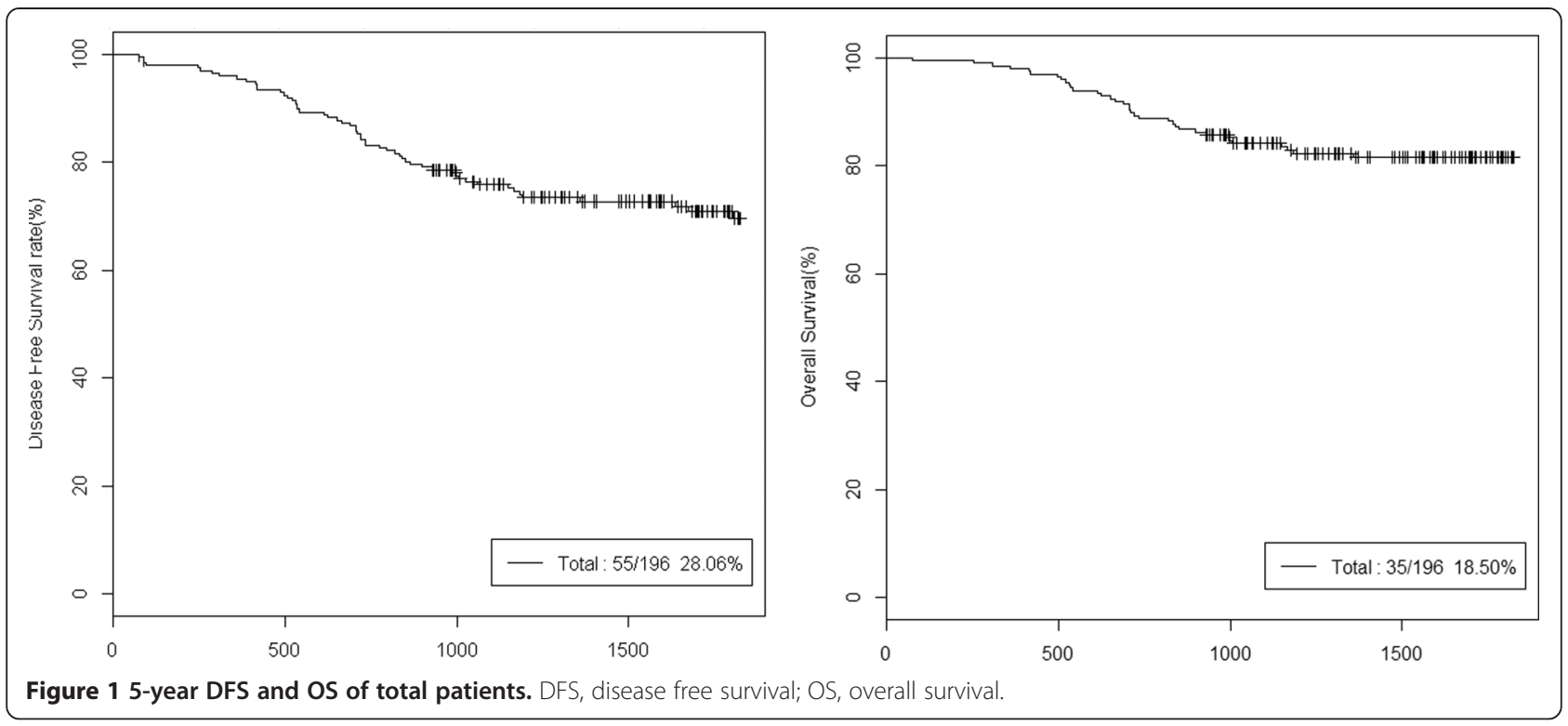

$70.62 \%$, respectively. And the 5-year OS rates of the high-risk stages II and III were $91.67 \%$ and $79.17 \%$, respectively (Figure 2).

In the univariate analysis, prognostic factors for DFS were T4 stage $(p=0.0018)$, preoperative anemia $(p=$ $0.0019)$, and preoperative thrombocytopenia $(p=0.0444)$, and prognostic factors for OS were T4 stage $(p=0.005)$, preoperative anemia $(p=0.0143)$, preoperative thrombocytopenia $(p=0.0485)$, postoperative carcinoembryonic antigen (CEA) $(p=0.0019)$, and low albumin level $(p=$ 0.0298) (Table 2). Statistically significant factors in the univariate analysis were included in a multivariate analysis.
In the multivariate analysis, prognostic factors for DFS were T4 stage $(p=0.0032)$ and preoperative anemia $(p=$ 0.0043 ) (Table 3). And the prognostic factors for OS were T4 stage $(p=0.0124)$, postoperative CEA $(p=0.0032)$, and preoperative anemia $(p=0.0313)$ (Table 4$)$.

Prognostic models were prepared using the two common prognostic factors, T4 stage and preoperative anemia. These prognostic models were classified into the following three groups: 1) low-risk group without either of these prognostic factors, 2) intermediate-risk group with only one prognostic factor, and 3) high-risk group with both prognostic factors. Each patient group who had no prognostic value (low-risk group), single
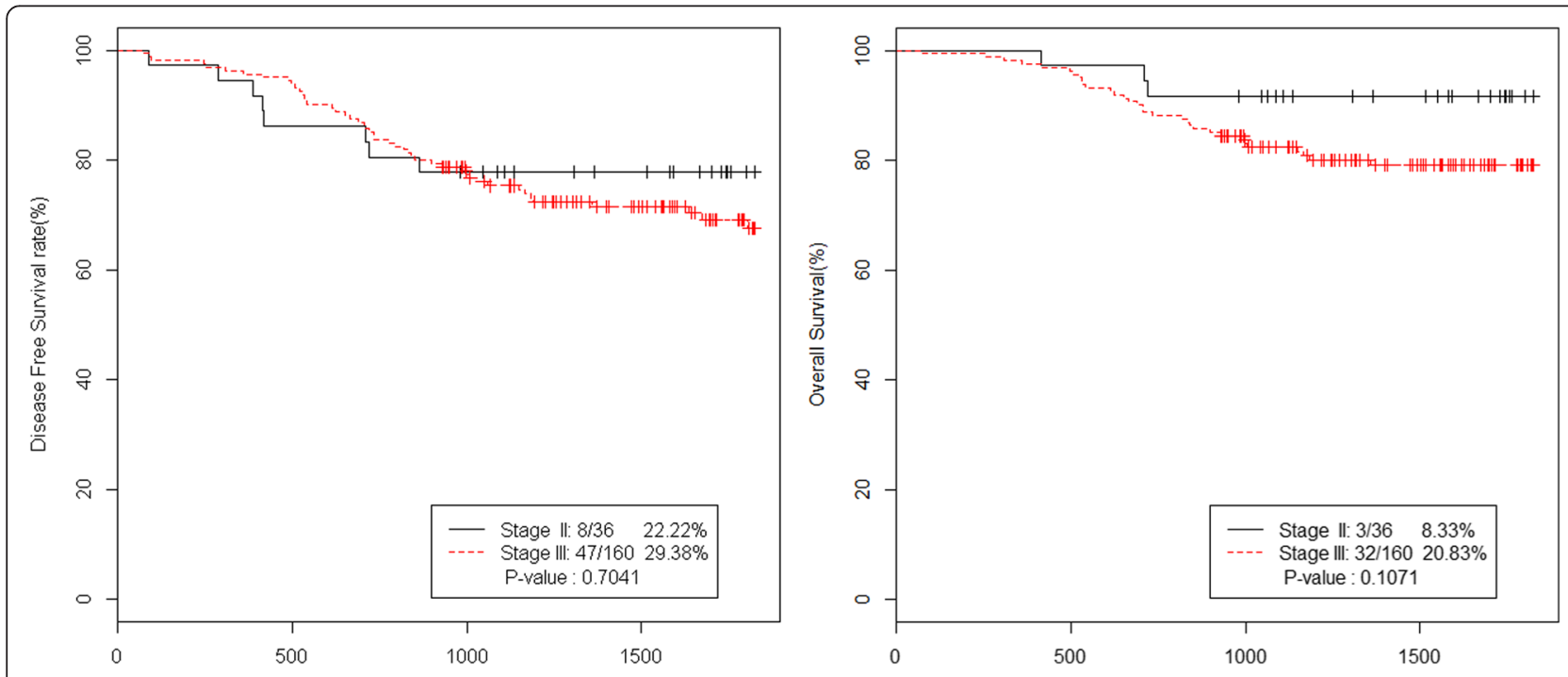

Figure 2 5-year DFS and OS of stage II vs. stage III. DFS, disease free survival; OS, overall survival. 
Table 2 Univariate analysis of prognostic factors for DFS and OS

\begin{tabular}{|c|c|c|c|}
\hline Factor & Classification & $\begin{array}{l}p \text { value } \\
\text { (DFS) }\end{array}$ & $\begin{array}{l}p \text { value } \\
(\mathrm{OS})\end{array}$ \\
\hline \multirow[t]{2}{*}{ Sex } & Female & & \\
\hline & Male & 0.9818 & 0.8802 \\
\hline \multirow[t]{2}{*}{ Age } & $<65$ & & \\
\hline & $\geq 65$ & 0.5093 & 0.8196 \\
\hline \multirow[t]{4}{*}{ Cancer location } & Right & & \\
\hline & Transverse & 0.2048 & 0.0534 \\
\hline & Descending & 0.2056 & 0.5503 \\
\hline & $\begin{array}{l}\text { Sigmoid and } \\
\text { rectosigmoid }\end{array}$ & 0.7813 & 0.9634 \\
\hline \multirow[t]{2}{*}{ Lymphovascular invasion } & Negative & & \\
\hline & Positive & 0.4643 & 0.2176 \\
\hline \multirow[t]{2}{*}{ Neural invasion } & Negative & & \\
\hline & Positive & 0.3234 & 0.6679 \\
\hline \multirow[t]{5}{*}{ Histology (differentiation ) } & Well & & \\
\hline & Moderately & 0.5575 & 0.9728 \\
\hline & Poorly & 0.9001 & 0.894 \\
\hline & Signet ring cell & 0.1424 & 0.1516 \\
\hline & Mucinous cell & 0.8841 & 0.8773 \\
\hline \multirow[t]{2}{*}{ WBC } & $\begin{array}{l}4,000 \sim 10,000 \times \\
10^{6} / \mathrm{L}\end{array}$ & & \\
\hline & $<4,000 \times 10^{6} / \mathrm{L}$ & 0.8888 & 0.9328 \\
\hline \multirow[t]{2}{*}{$\mathrm{Hgb}$} & Normal & & \\
\hline & Anemia & 0.0019 & 0.0143 \\
\hline \multirow[t]{3}{*}{ PLT } & $140 \sim 440 \times 10^{9} / \mathrm{L}$ & & \\
\hline & Thrombocytopenia & 0.0444 & 0.0485 \\
\hline & $>440 \times 10^{9} / \mathrm{L}$ & 0.6451 & 0.7521 \\
\hline \multirow[t]{2}{*}{ Albumin } & $3.8 \sim 5.3 \mathrm{~g} / \mathrm{dL}$ & & \\
\hline & $<3.8 \mathrm{~g} / \mathrm{dL}$ & 0.3055 & 0.0298 \\
\hline \multirow[t]{2}{*}{ LDH } & $129 \sim 240 \mathrm{U} / \mathrm{L}$ & & \\
\hline & $>240 \mathrm{U} / \mathrm{L}$ & 0.1801 & 0.2756 \\
\hline \multirow[t]{2}{*}{ Total bilirubin } & $0.2 \sim 1.0 \mathrm{mg} / \mathrm{dL}$ & & \\
\hline & $>1.0 \mathrm{mg} / \mathrm{dL}$ & 0.2247 & 0.8442 \\
\hline \multirow[t]{2}{*}{ AST } & $10 \sim 33 \mathrm{U} / \mathrm{L}$ & & \\
\hline & $>33 \mathrm{U} / \mathrm{L}$ & 0.1258 & 0.4506 \\
\hline \multirow[t]{2}{*}{ ALT } & $4 \sim 50 \mathrm{U} / \mathrm{L}$ & & \\
\hline & $>50 \mathrm{U} / \mathrm{L}$ & 0.4121 & 0.7752 \\
\hline \multirow[t]{2}{*}{ Protein } & $6.7 \sim 8.3 \mathrm{~g} / \mathrm{dL}$ & & \\
\hline & $<6.7 \mathrm{~g} / \mathrm{dL}$ & 0.3451 & 0.3746 \\
\hline \multirow[t]{4}{*}{ T stage } & 1 & & \\
\hline & 2 & & \\
\hline & 3 & & \\
\hline & 4 & 0.0018 & 0.005 \\
\hline
\end{tabular}

Table 2 Univariate analysis of prognostic factors for DFS and OS (Continued)

\begin{tabular}{|c|c|c|c|}
\hline \multirow[t]{3}{*}{ N stage } & 0 & & \\
\hline & 1 & 0.2954 & 0.4345 \\
\hline & 2 & 0.6658 & 0.1171 \\
\hline \multirow[t]{2}{*}{ Preoperative CEA } & $\leq 5 \mathrm{ng} / \mathrm{mL}$ & & \\
\hline & $>5 \mathrm{ng} / \mathrm{mL}$ & 0.4768 & 0.2144 \\
\hline \multirow[t]{2}{*}{ Postoperative CEA } & $\leq 5 \mathrm{ng} / \mathrm{mL}$ & & \\
\hline & $>5 \mathrm{ng} / \mathrm{mL}$ & 0.0585 & 0.0019 \\
\hline \multirow[t]{3}{*}{ ASA score } & 1 & & \\
\hline & 2 & 0.31 & 0.7768 \\
\hline & 3 & 0.7646 & 0 \\
\hline \multirow[t]{2}{*}{ Neutropenia } & Absent & & \\
\hline & Present & 0.7597 & 0.1927 \\
\hline \multirow{2}{*}{$\begin{array}{l}\text { Gl Symptom (diarrhea, nausea, } \\
\text { anorexia) }\end{array}$} & Absent & & \\
\hline & Present & 0.6714 & 0.508 \\
\hline
\end{tabular}

ALT, alanine aminotransferase; ASA, American Society of Anesthesiologists; AST, aspartate aminotransferase; CEA, carcinoembryonic antigen; Gl symptoms, gastrointestinal symptoms (diarrhea, constipation, anorexia); Hgb, hemoglobin; $\mathrm{LDH}$, lactate dehydrogenase; PLT, platelet; WBC, white blood cell.

(intermediate-risk group), or both factors (high-risk group) revealed $95.35 \%, 69.06 \%$, and $28.57 \%$ in the 5 year DFS rate, respectively $(p<0.0001)$. The 5 -year OS rate also showed the significant differences in each group who had no prognostic value (low-risk group), single (intermediate-risk group), or both factors (highrisk group) revealed $100 \%, 79.3 \%$, and $45.92 \%$, respectively $(p<0.0001)$ (Figure 3$)$. The multivariate analysis of each risk group for DFS showed that the hazard ratio (HR) of the intermediate-risk group was 7.401 (95\% confidence interval (CI) 1.786 to $30.67, p=0.0058$ ) and that of the high-risk group was 19.296 (95\% CI 4.197 to 88.723, $p=0.0001$ ) (Table 3).

\section{Discussion}

We assessed the 5-year DFS rate, 5-year OS rate, and prognostic factors that affected treatment of patients with colon cancer in the high-risk stage II group and patients in stage III. These patients underwent adjuvant FOLFOX4 chemotherapy after surgery. Numerous studies have reported that adjuvant chemotherapy after radical surgery improves the survival rate of patients with stage III colon cancer [6-9].

In the MOSAIC trial, the 5-year DFS rate for patients with stage III colon cancer, who underwent adjuvant FOLFOX chemotherapy, was $73.3 \%$. This figure was superior to the $67.4 \% 5$-year DFS rate of LV5FU5 chemotherapeutic regimen (HR $0.80,95 \%$ CI 0.68 to $0.93, p=$ $0.003)[8,11]$. However, no significant differences were observed between the two groups in the 5-year DFS rate or overall survival rate of patients with stage II colon 
Table 3 Multivariate analysis of prognostic factors for DFS

\begin{tabular}{|c|c|c|c|c|c|}
\hline \multirow{2}{*}{$\frac{\text { Factor }}{\text { T stage }}$} & \multirow{2}{*}{$\begin{array}{l}\text { Classification } \\
1\end{array}$} & \multirow[t]{2}{*}{ Hazard ratio } & \multicolumn{2}{|c|}{$95 \%$ confidence interval } & \multirow[t]{2}{*}{$p$ value } \\
\hline & & & & & \\
\hline & 2 & 0 & 0 & & \\
\hline & 3 & 0 & 0 & & \\
\hline & 4 & 2.747 & 1.402 & 5.383 & 0.0032 \\
\hline \multirow[t]{2}{*}{$\mathrm{Hgb}$} & Normal & & & & \\
\hline & Anemia & 5.505 & 1.708 & 17.745 & 0.0043 \\
\hline \multirow[t]{3}{*}{ PLT } & $140 \sim 440 \times 10^{9} / L$ & & & & \\
\hline & Thrombocytopenia & 3.213 & 0.976 & 10.581 & 0.0549 \\
\hline & $>440 \times 10^{9} / \mathrm{L}$ & 1.14 & 0.273 & 4.758 & 0.8574 \\
\hline \multirow[t]{2}{*}{ Postoperative CEA } & $\leq 5$ & & & & \\
\hline & $>5$ & 1.672 & 0.91 & 3.073 & 0.0975 \\
\hline \multirow[t]{3}{*}{ Prognostic model (T4-Hgb) } & Low risk & & & & \\
\hline & Intermediate risk & 7.401 & 1.786 & 30.67 & 0.0058 \\
\hline & High risk & 19.296 & 4.197 & 88.723 & 0.0001 \\
\hline
\end{tabular}

CEA, carcinoembryonic antigen; Hgb, hemoglobin; PLT, platelet.

cancer $[8,12]$. The National Surgical Adjuvant Breast and Bowel Project (NSABP) C-07 trial compared the oncologic outcomes of FLOX (oxaliplatin + leucovorin + fluorouracil) and FULV (leucovorin + fluorouracil), adjuvant chemotherapeutic regimens, in patients with stage III colon cancer. The 5-year DFS rate of the group treated with FLOX chemotherapy was $69.4 \%$, whereas that of the group treated with FULV chemotherapy was 64.2\% (HR 0.82, 95\% CI 0.72 to $0.93, p<0.001$ ) $[11,13]$. We investigated 196 patients, belonging to the high-risk stage II or stage III groups, who underwent adjuvant FOLFOX4 chemotherapy after radical surgery, and found a 5-year DFS rate of $71.94 \%$ and 5-year OS rate of $81.5 \%$. The 5-year DFS and 5-year OS rate of the 160 patients in stage III showed $70.62 \%$ and $79.17 \%$, separately. This outcome was similar to that of the MOSAIC or NSABP C-07 trials, representative investigations in which oxaliplatin was added to the FULV chemotherapeutic regimen.

There are numerous variables for the candidates for the prognostic factors of FOLFOX chemotherapy. McMillan et al. [14] reported that not only objective cancer staging but also nutritional state and factors reflecting systemic inflammation (weight loss, CRP increase, or decreased albumin) affect the prognosis after cancer treatment. Lee et al. [15] analyzed prognostic factors in 1,455 patients with progressive gastric cancer, who were treated with taxotere, taxol, FOLFOX, FOLFIRI, or FOLFOXIRI chemotherapeutic regimens. They reported that decreased albumin, increased alkaline phosphatase, bone metastasis, or ascites adversely affected the survival rate. But we chose the three categories affecting adjuvant FOLFOX4 chemotherapy according to 1) patients' clinical characteristics, 2) preoperative laboratory

Table 4 Multivariate analysis of prognostic factors for OS

\begin{tabular}{|c|c|c|c|c|c|}
\hline \multirow{2}{*}{$\frac{\text { Factor }}{\text { T stage }}$} & \multirow{2}{*}{$\begin{array}{l}\text { Classification } \\
1\end{array}$} & \multirow[t]{2}{*}{ Hazard ratio } & \multicolumn{2}{|c|}{$95 \%$ confidence interval } & \multirow[t]{2}{*}{$p$ value } \\
\hline & & & & & \\
\hline & 2 & 0 & 0 & & \\
\hline & 3 & 0 & 0 & & \\
\hline & 4 & 2.904 & 1.259 & 6.697 & 0.0124 \\
\hline \multirow[t]{2}{*}{$\mathrm{Hgb}$} & Normal & & & & \\
\hline & Anemia & 9.01 & 1.219 & 66.62 & 0.0313 \\
\hline \multirow[t]{3}{*}{ PLT } & $140 \sim 440 \times 10^{9} / \mathrm{L}$ & & & & \\
\hline & Thrombocytopenia & 2.288 & 1.04 & 8.882 & 0.0654 \\
\hline & $>440 \times 10^{9} / \mathrm{L}$ & 1.244 & 0.374 & 4.136 & 0.7221 \\
\hline \multirow[t]{2}{*}{ Postoperative CEA } & $\leq 5$ & & & & \\
\hline & $>5$ & 2.961 & 1.439 & 6.095 & 0.0032 \\
\hline
\end{tabular}

CEA, carcinoembryonic antigen; Hgb, hemoglobin; PLT, platelet. 

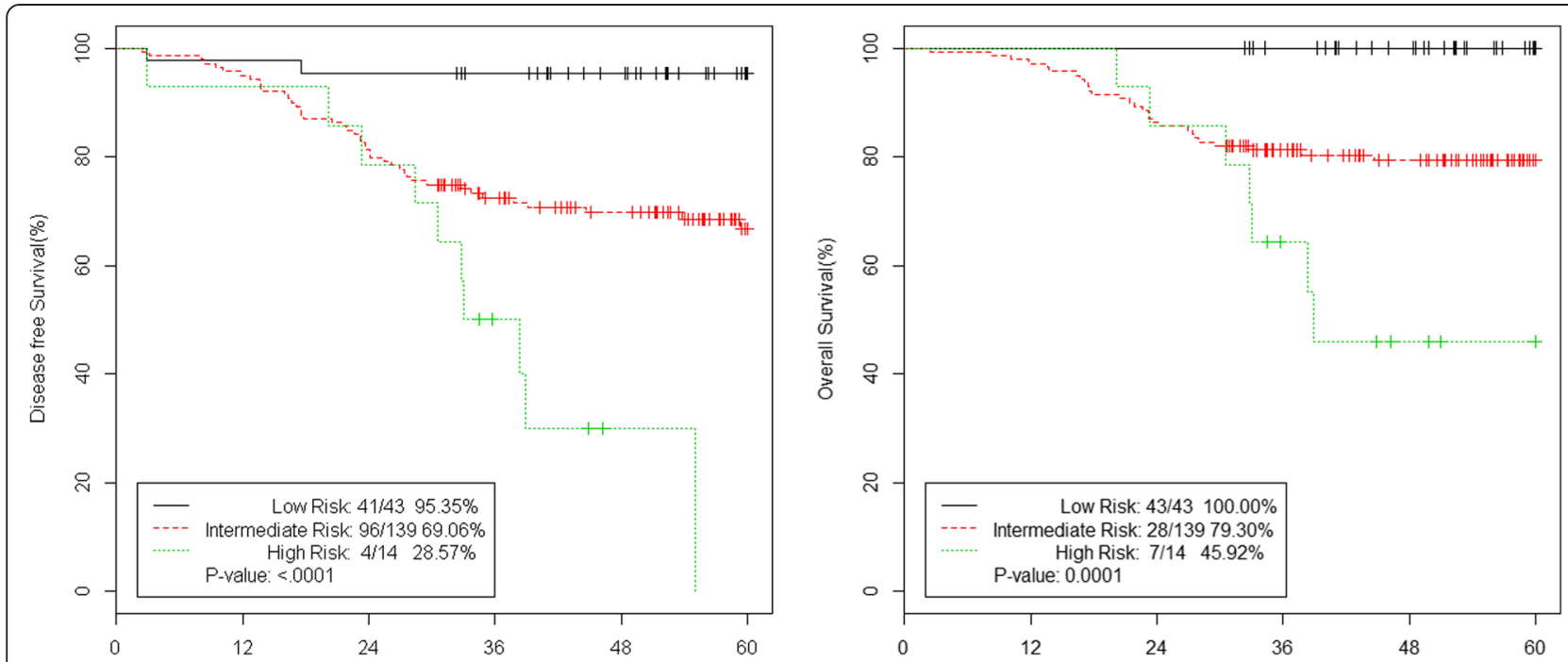

Figure 3 5-year DFS and OS of low vs. intermediate vs. high-risk group. DFS, disease free survival; OS, overall survival.

findings regarding the general condition of patients before undergoing treatment, and 3) postsurgical pathologic features. In this study, the multivariate analysis showed that T4 stage and preoperative anemia were the significant prognostic factors for both DFS and OS. Snaebjornsson et al. [16] reported that pT4 stage, among many variables analyzed in patients with stages II and III colon cancer, is the most important indicator of a poor prognosis. They also reported that it had significance equal to that of lymph node status. In a comparison of stages pT4 and pT3 among 352 patients with stage II colon cancer, the 5year survival rates were $50 \%$ and $82 \%$, respectively (HR 2.92, 95\% CI 1.67 to $5.10, p<0.001)$. Gunderson et al. [17] reported that pT4N0M0 stage II tumors have a poorer prognosis than pT1-2 N1-2 M0 stage III tumors. Thus, pT4 stage is a rather important independent prognostic factor in the treatment of colon cancer. Pretreatment anemia is associated with poor prognosis in variable cancers such as lung cancer, cervical cancer, head and neck cancer, and esophageal cancer [18-21]. Qiu et al. reported that pretreatment anemia (HR $0.084,95 \%$ CI 0.037 to $0.191, p<0.001$ ) and thrombocytosis (HR 3.475, 95\% CI 1.564 to $7.721, p=0.002)$ in colorectal cancer patients might be useful prognostic markers [22]. Anemia in colorectal cancer patients is thought to be due to inflammatory cytokines and occult bleeding, and anemia can cause intratumoral hypoxia [23]. Intratumoral hypoxia might be an important factor in the activation of hypoxia-inducible factor-1, which can contribute in the acceleration of tumor metastasis [24]. We also established a prognostic model using T4 stage and preoperative anemia. The highrisk group (HR 19.296, 95\% CI 4.197 to 88.723, $p=$ 0.0001) with both factors, T4 stage, and preoperative anemia showed a significantly worse prognosis than the other two groups.

\section{Conclusion}

In conclusion, our results showed similar efficacy to the MOSAIC study in stage II and stage III colon cancer patients treated with adjuvant FOLFOX chemotherapy after curative resection. Patients who had T4 stage and/ or preoperative anemia showed worse prognosis than patients without any prognostic value. These findings suggest that FOLFOX could not be effective in the patients with T4 stage colon cancer accompanied by preoperative anemia. Therefore, much caution and aggressive additional adjuvant treatment should be used when treating T4 stage colon cancer patients accompanied by preoperative anemia with FOLFOX-based adjuvant chemotherapy.

\section{Competing interests}

The authors declare that they have no competing interests.

\section{Author's contributions}

MSA and KBB participated in the design and writing of the study. JHY, KHK, JWH, JHK, BMK, and MKO collected data and analysis. CSC, MSK, and KHH revised manuscript with the additional references. All authors read and approved the final manuscript.

\section{Author's information}

Min Sung An is the first author.

\section{Acknowledgements}

This work was supported by Inje Research and Scholarship Foundation in 2014.

\section{Author details}

'Department of Surgery, Busan Paik Hospital, Inje University College of Medicine, 75 Bokji-ro, Busanjin-gu, Busan 614-735, Korea. ²Iternal medicine, Busan Paik Hospital, Inje University College of Medicine, 75 Bokji-ro, 
Busanjin-gu 614-735, Korea. ${ }^{3}$ Pathology, Busan Paik Hospital, Inje University College of Medicine, 75 Bokji-ro, Busanjin-gu 614-735, Korea. ${ }^{4}$ Clinical Trial Center in Pharmacology, Busan Paik Hospital, Inje University College of Medicine, 75 Bokji-ro, Busanjin-gu 614-735, Korea.

Received: 29 May 2014 Accepted: 26 January 2015

Published online: 19 February 2015

\section{References}

1. Jung KW, Park SH, Won YJ, Kong HJ, Lee JY, Seo HG, et al. Prediction of cancer incidence and mortality in Korea, 2012. Cancer Res Treat. 2012;44(1):25-31.

2. Obrand $\mathrm{DI}$, Gordon $\mathrm{PH}$. Incidence and patterns of recurrence following curative resection for colorectal carcinoma. Dis Colon Rectum. 1997;40:15-24.

3. O'Connell JB, Maggard MA, Ko CY. Colon cancer survival rates with the new American Joint Committee on Cancer sixth edition staging. J Natl Cancer Inst. 2004;96:1420-5.

4. O'Connell MJ, Mailliard JA, Kahn MJ, Macdonald JS, Haller DG, Mayer RJ, et al. Controlled trial of fluorouracil and low-dose leucovorin given for 6 months as postoperative adjuvant therapy for colon cancer. J Clin Oncol. 1997;15:246-60.

5. Moertel CG, Fleming TR, Macdonald JS, Haller DG, Laurie JA, Goodman PJ, et al. Levamisole and fluorouracil for adjuvant therapy of resected colon carcinoma. N Engl J Med. 1990;322:352-8.

6. Wolmark N, Rockette H, Fisher B, Wickerham DL, Redmond C, Fisher ER, et al. The benefit of leucovorin-modulated fluorouracil as postoperative adjuvant therapy for primary colon cancer: result from National Surgical Adjuvant Breast and Bowel Project protocol C-03. J Clin Oncol. 1993;11:1879-87.

7. Andre T, Colin P, Louvet C, Gamelin E, Bouche O, Achille E, et al Semimonthly versus monthly regimen of fluorouracil and leucovorin administered for 24 or 36 weeks as adjuvant therapy in stage II and III colon cancer: results of a randomized trial. J Clin Oncol. 2003;21:2896-903.

8. Andre T, Boni C, Mounedji-Boudiaf L, Navarro M, Tabernero J, Hickish T, et al. Oxaliplatin, fluorouracil, and leucovorin as adjuvant treatment for colon cancer. N Engl J Med. 2004;350:2343-51.

9. Andre T, Boni C, Navarro M, Tabernero J, Hickish T, Topham C, et al. Improved overall survival with oxaliplatin, fluorouracil, and leucovorin as adjuvant treatment in stage II or III colon cancer in the MOSAIC trial. J Clin Oncol. 2009:27:3109-16.

10. NCCN Clinical Practice Guidelines in Oncology Colon Cancer version 3. 2014

11. Kuebler JP, Wieand HS, O'Connell MJ, Smith RE, Colangelo LH, Yothers G, et al. Oxaliplatin combined with weekly bolus fluorouracil and leucovorin as surgical adjuvant chemotherapy for stage II and III colon cancer: results from NSABP C-07. J Clin Oncol. 2007:25:2198-204.

12. Andre T, Tournigand C, Achille E, Tubiana-Mathieu N, Lledo G, Raoul Y, et al. Adjuvant treatment of colon cancer MOSAIC study's main results. Bull Cancer. 2006;93 Suppl 1:S5-9.

13. Yothers G, O'Connell MJ, Allegra CJ, Kuebler JP, Colangelo LH, Petrelli NJ et al. Oxaliplatin as adjuvant therapy for colon cancer: updated results of NSABP C-07 trial, including survival and subset analyses. J Clin Oncol. 2011;29:3768-74.

14. McMillan DC. An inflammation-based prognostic score and its role in the nutrition-based management of patients with cancer. Proc Nutr Soc 2008;67(3):257-62

15. Lee J, Lim T, Uhm JE, Park KW, Park SH, Lee SC, et al. Prognostic model to predict survival following first-line chemotherapy in patients with metastatic gastric adenocarcinoma. Ann Oncol. 2007;18:886-91.

16. Snaebjornsson P, Coupe VM, Jonasson L, Meijer GA, van Grieken NC, Jonasson JG. pT4 stage II and III colon cancers carry the worst prognosis in a nationwide survival analysis. Shepherd's local peritoneal involvement revisited. Int J Cancer. 2014;135:467-78.

17. Gunderson LL, Jessup JM, Sargent DJ, Greene FL, Stewart AK. Revised TN categorization for colon cancer based on national survival outcomes data. J Clin Oncol. 2010;28:264-71.

18. Caro JJ, Salas M, Ward A, Goss G. Anemia as an independent prognostic factor for survival in patients with cancer: a systemic, quantitative review. Cancer. 2001:91:2214-21.

19. Dunst J, Kuhnt T, Strauss HG, Krause U, Pelz T, Koelbl H, et al. Anemia in cervical cancers: impact on survival, patterns of relapse, and association with hypoxia and angiogenesis. Int J Radiat Oncol Biol Phys. 2003;56:778-87.
20. Baghi M, Wagenblast J, Hambek M, Moertel S, Gstoettner W, Strebhardt K, et al. Pre-treatment haemoglobin level predicts response and survival after TPE induction polychemotherapy in advanced head and neck cancer patients. Clin Otolaryngol. 2008;33:245-51.

21. Rades D, Schild SE, Bahrehmand R, Zschenker O, Alberti WA, Rudat VR. Prognostic factors in the nonsurgical treatment of esophageal carcinoma with radiotherapy or radiochemotherapy: the importance of pretreatment hemoglobin levels. Cancer. 2005;103:1740-6.

22. Qiu MZ, Yuan ZY, Luo HY, Ruan DY, Wang ZQ, Wang FH, et al. Impact of pretreatment hematologic profile on survival of colorectal cancer patients. Tumor Biol. 2010;31:255-60.

23. Gabay C, Kushner I. Acute-phase proteins and other systemic responses to inflammation. N Engl J Med. 1999;340:248-54.

24. Yang MH, Wu MZ, Chiou SH, Chen PM, Chang SY, Liu CJ, et al. Direct regulation of TWIST by HIF-1 alpha promotes metastasis. Nat Cell Biol. 2008;10:295-305

\section{Submit your next manuscript to BioMed Central and take full advantage of:}

- Convenient online submission

- Thorough peer review

- No space constraints or color figure charges

- Immediate publication on acceptance

- Inclusion in PubMed, CAS, Scopus and Google Scholar

- Research which is freely available for redistribution 